\title{
Low uptake of cervical cancer screening among HIV positive women in Gondar University referral hospital, Northwest Ethiopia: cross-sectional study design
}

\author{
Abebe Dires Nega ${ }^{1}$, Mulat Adefris Woldetsadik ${ }^{2}$ and Abebaw Addis Gelagay ${ }^{3 *}$ (D)
}

\begin{abstract}
Background: Cervical cancer is one of the leading causes of death in women worldwide. Majority of the cases are found in developing countries. The increasing risk of cervical cancer death and the high prevalence of human papilloma virus (HPV) infection in Human immuno-deficiency virus(HIV) positive women calls for determining the level of premalignant cervical cancer (Ca) screening uptake. So, this study aimed to assess the uptake of cervical cancer screening and its associated factors.
\end{abstract}

Methods: An institution based cross sectional study was conducted from April to May, 2016, among adult HIV positive women attending care and treatment at Gondar University Referral Hospital. The data were collected using an interviewer administered questionnaire.

Bivariate and multivariable logistic regression analyses were used to determine the presence and the degree of association between dependent and independent variables. In the multivariable logistic analysis, a $P$-value of $<0.05$ and odds ratio with a 95\% confidence interval were considered to determine independent predictors for the uptake of cervical cancer(Ca) screening.

Results: The life-time uptake of cervical cancer screening among HIV positive women was 10\% (95\% Confidence Interval(Cl): 7.3-12.8). In multivariable the analysis, women with primary education (Adjusted Odds Ratio(AOR) $=3.92$, 95\%Cl:1.70-8.99), secondary education ( $\mathrm{AOR}=3.84,95 \% \mathrm{Cl}: 1.50-9.83)$, and tertiary level education ( $\mathrm{AOR}=4.16,95 \% \mathrm{Cl}: 1$. 24-13.98), having a child ( $\mathrm{AOR}=3.02,95 \% \mathrm{Cl}: 1.23-7.46)$, diagnosed as HIV positive ten years back or more ( $\mathrm{AOR}=2.71$, 95\% Cl: 1.06-6.97), and Cell Differentiation 4(CD4) count of less than or equal to 200cell/mm3 (AOR=5.29, 95\% Cl: 2. 58-10.83) were significantly associated with the uptake of cervical cancer screening.

Conclusion: In this study, the uptake of cervical cancer screening was very low. Educational status, parity, length of time after diagnosis as HIV positive, and CD4 count are important predictors of cervical cancer screening. Health care workers and cervical cancer prevention and control program coordinators and implementers need to provide counseling services for all Anti-retroviral Therapy(ART) care attendants. So as to explore the root causes for the low utilization of precancerous stage of cervical Ca screening service, conducting a study on the supply side with a qualitative component is mandatory.

Keywords: Cervical cancer, Screening, HIV positive women, Ethiopia

\footnotetext{
* Correspondence: abebaw.addis@gmail.com

${ }^{3}$ College of Medicine and Health Science, Reproductive Health Department,

University of Gondar, Gondar City, Ethiopia

Full list of author information is available at the end of the article
}

(c) The Author(s). 2018 Open Access This article is distributed under the terms of the Creative Commons Attribution 4.0 International License (http://creativecommons.org/licenses/by/4.0/), which permits unrestricted use, distribution, and reproduction in any medium, provided you give appropriate credit to the original author(s) and the source, provide a link to the Creative Commons license, and indicate if changes were made. The Creative Commons Public Domain Dedication waiver (http://creativecommons.org/publicdomain/zero/1.0/) applies to the data made available in this article, unless otherwise stated. 


\section{Background}

Cancer is an abnormal growth of body cells [1]. Globally, cervical cancer is one of the most common (ranks fourth) cancer in women. The 2012 estimate noted that around half a million $(528,000)$ new cervical cancer cases and more than a quarter of a million $(266,000)$ deaths occurred due to cervical cancer globally. The burden of the disease and death from cervical cancer is very high in developing countries [2]. Cervical cancer is the second most common cancer in women living in less developed regions, with an estimated 445, 000 new cases in 2012 [3].

Globally, more than 2.7 million women are at risk of cervical cancer, out of which about $80 \%$ were found in less developed regions [4]. The estimated incidence rate of cervical cancer in 2012 ranged from 4.4 per 100,000 in Western Asia to 42.7 per 100,000 in Eastern Africa [2]. In Ethiopia, cervical cancer is the second leading cause of female cancer and female cancer death. The 2012 estimate showed that the age-standardized incidence rates of cervical cancer of Ethiopia $=26.4 / 100,000$ women. The same estimate noted that about 4732 cervical cancer deaths occurred annually and age-standardized mortality rate of the problem was $18.4 / 100,000$ in the country [5].

Cervical cancer is caused by a sexually acquired infection with certain types of HPV. Nearly $70 \%$ of the cervical cancer $(\mathrm{Ca})$ is caused by $\mathrm{HPV}$ (Human Papilloma Virus) of type 16 and type $18[3,6]$.

According to the 2015 report from Information Centre on HPV and Cancer, around 29.43million women ( $>=15$ years of age) were at risk of Cervical Ca in Ethiopia [7]. Early first sexual intercourse, multiple sexual partners, and immune suppression are the main risk factors for HPV persistence and development of cervical cancer [3]. HIV positive women have a higher incidence of persistent HPV infection which leads to an increased risk of developing premalignant lesion of the cervix. The risk of developing invasive Cervical $\mathrm{Ca}$ in HIV positive women is ten years earlier than HIV negative women [8].

The detection rate of pre cervical lesion was higher among HIV sero-positive women than among non-HIV infected women. Studies in USA [9], Kenya [10], and Zambia [11], reported the contrast as 5\% Vs 2, 25\% Vs 19 , and $41 \%$ Vs $20 \%$, respectively.

Cervical cancer is the only gynecologic cancer for which screening test is available that can detect its pre-cancerous stage. The World Health Organization recommended that cervical cancer screening is needed for women aged 30-49 years irrespective of their HIV sero-status. It is also recommended that sexually active girls and women need to be screened as soon as they are diagnosed as positive for HIV [12].

In Ethiopia, visual inspection with acetic acid(VIA) as a screening tool and cryotherapy as a treatment modality for premalignant cervical lesion are available in some hospitals [13]. The service is mainly for HIV positive women. However, there is limited information about the level of cervical cancer screening service utilization in Ethiopia in general and in the study area in particular. Therefore, this study aimed to assess the uptake of cervical $\mathrm{Ca}$ screening and associated factors among HIV positive women. Thus, it is expected to help policy/decision makers, non-government organizations (NGOs), health care providers, and community service providers design strategies and take necessary interventions accordingly.

\section{Methods}

\section{Study design and period}

An institution- based cross sectional study was conducted among HIV positive women attending adult ART (Anti-Retroviral Therapy) Clinic at Gondar University Referral Hospital, northwest Ethiopia, from April 16 to May 15, 2016.

\section{Study area}

The study was conducted at Gondar University Referral Hospital, in the chronic HIV care and treatment clinic, Gondar. Gondar city is found in the Amhara Regional State, $727 \mathrm{~km}$ from Addis Ababa, the capital of Ethiopia. According to the 2007 census conducted by the Central Statistical Agency of Ethiopia, Gondar had a total population of 206, 987 and more than half $(108,902)$ were females. The city had one teaching referral hospital, namely the University of Gondar Referral Hospital which was providing services to more than five million people. The HIV care service of the hospital was established in 2003 Gregorian calendar (GC) and has three clinics: Adult ART, pediatric ART, and Volunteer Counseling and Testing (VCT). There were about 9565 HIV positive clients enrolled in the adult ART Clinic. From these, 4731 clients were on Highly Active Antiretroviral Therapy (HAART). Before the emergence of visual inspection with acetic acid (VIA) for cervical Ca screening, pap smear was used. However, it was not routinely used for all HIV positive women. Instead, the physician ordered the pap smear only for women who were suspected for or have symptoms of cervical Ca irrespective of their HIV sero-status. Premalignant cervical cancer screening by visual inspection with acetic acid (VIA) and cryotherapy services have been available in the Hospital since 2013. In principle, the screening service for precancerous cervical lesion using VIA has to be given routinely to all HIV positive women free of charge and the screening service can be repeated every three year. However, what is actually being done is that providers selectively order/direct some women to 
screen. Trained nurses and physicians, who are assigned in the ART clinic, have the responsibility to provide information, education, and counseling (IEC) and the screening service.

\section{Study population}

All HIV positive women aged 18 years and above and were receiving care in the Adult ART Clinic during the study period were the study population.

\section{Sample size determination}

A single population proportion formula $\left[\mathrm{n}=\left(\mathrm{Z}_{\alpha / 2}\right)^{2}\right.$ * $\left.\mathrm{p}(1-\mathrm{p}) / \mathrm{d}^{2}\right]$ was used to estimate the sample size. By considering the findings of a study conducted in Ethiopia and the following assumptions: proportion of cervical $\mathrm{Ca}$ screening uptake among HIV positive women $=12 \%$ [14], $3 \%$ margin of error, and a 95\% confidence level, the required sample size was 451 . Sample size was also calculated from more frequently observed associated factors for the uptake of Cervical Ca screening, like age and educational status $[8,12]$ using epi info StatCalc and became 52 and 192, respectively. Finally, the larger sample size of 496 was selected by considering a10\% non-response rate.

\section{Sampling procedure}

Out of all clients attending the Adult ART Chronic Follow-up Clinic, the average monthly number of women was estimated by considering the number of service users in the past six months. Using a systematic random sampling technique, every 5 th woman on the list of their order of arrival for follow up care was selected and formed the participants of the study.

\section{Operational definitions:}

- Uptake of cervical cancer screening: HIV positive women who were screened for premalignant cervical lesion at least once in their life time (self-reported).

- Awareness of cervical cancer screening: HIV positive women who had heard about cervical cancer and cervical Ca screening.

\section{Data collection tool and procedure}

The questionnaire was prepared in English (Additional file 1) and translated to Amharic (Additional file 2). The local language, and then retranslated to English by language experts. Four first degree graduate nurses were employed for data collection. A one day training was given to data collectors on the methods, objectives, and the tool before collection began. The tool was pre-tested on 20 cases at a nearby Azezo Health Center to see the accuracy of responses, the clarity of language and the appropriateness of the tool. Every 5th woman in the order of arrival for follow up care were given information about the study and were requested to participate. After obtaining consent, data were collected using the interviewer administered questionnaire. Patients chart (medical record) was also reviewed to obtain clinical parameters, such as the WHO (World Health Organization) clinical staging for HIV infection and their CD4 count. The investigators checked the completeness of the questionnaire and conducted the overall supervision on a daily base.

\section{Data processing and analysis}

The collected data were checked and coded manually and entered into Epi-info version 7 and then exported to Statistical Package for Social Sciences (SPSS) version 20.0 for statistical analysis. Descriptive statistics and binary logistic regression analyses were done. In the bivariate analysis, variables which had significant association with the outcome variable at $0.2 p$-value were considered for multivariable analysis. The Back ward Wald method was employed in the multivariable analysis. In the multivariable logistic regression analysis, p-value less than 0.05 and adjusted odds ratio with a $95 \%$ confidence interval were used to determine the presence and degree of association between dependent and independent variables.

\section{Results}

Socio-demographic and economic characteristics of the respondents

A total of 496 HIV positive women were approached. Out of these, 460 women agreed to participate in the study (92.7\% response rate). The mean age of the study participants was 35.5 years (Standard deviation $(\mathrm{SD})= \pm$ 8.4) and 197(42.8\%) of the participants were found in the age range of 25-34 years. The majority of participants, 345(75\%), were Orthodox Christians; 282(61.3\%) were Amhara by ethnicity; 193(42.0\%) were married; 353 (76.7\%) were urban dwellers; $217(47.2 \%)$ had no formal education, and $311(67.6 \%)$ had at least one child (Table 1).

\section{Awareness of the study participants and their clinical profile} Half of the participants, 228 (49.6\%), heard about cervical cancer, and 174 (37.8\%) heard about premalignant cervical cancer screening. The majority, 409 (88.9\%), of the respondents were on a highly active antiretroviral therapy (HAART), and 388 (84.3\%) had CD4 count of > $200 / \mathrm{mm}^{3}$. Slightly more than a half(53.9\%)and nearly one third (32\%) of the participants were in WHO clinical stage I and II respectively. Very few (3\%) respondents were in stage IV.

\section{Uptake of cervical cancer screening}

In this study, the life time uptake of premalignant cervical cancer screening service was 10\% (95\% CI: 7.3-12.8), of 
Table 1 Socio-demographic and economic characteristics of HIV positive women attending adult ART clinic in Gondar university referral Hospital, Northwest Ethiopia, April $2016(n=460)$

\begin{tabular}{|c|c|c|}
\hline Variable & Category & Frequency (\%) \\
\hline \multirow[t]{5}{*}{ Age in year } & $18-24$ & $28(6.1 \%)$ \\
\hline & $25-34$ & $197(42.8 \%)$ \\
\hline & $35-44$ & 164 (35.7\%) \\
\hline & $45-54$ & 55 (12.0\%) \\
\hline & $>/=55$ & $16(3.5 \%)$ \\
\hline \multirow[t]{5}{*}{ Religion } & $\begin{array}{l}\text { Orthodox } \\
\text { Christian }\end{array}$ & $345(75 \%)$ \\
\hline & Muslim & 74 (16.1\%) \\
\hline & Catholic & $12(2.6 \%)$ \\
\hline & Protestant & $23(5.0 \%)$ \\
\hline & Others $^{\mathrm{a}}$ & $6(1.3 \%)$ \\
\hline \multirow[t]{5}{*}{ Ethnicity } & Amhara & $282(61.3 \%)$ \\
\hline & Kimant & 78 (17.0\%) \\
\hline & Tigray & $68(14.8 \%)$ \\
\hline & Oromo & $13(2.8 \%)$ \\
\hline & Others $^{b}$ & $19(4.1 \%)$ \\
\hline \multirow[t]{2}{*}{ Residence } & Urban & $353(76.7 \%)$ \\
\hline & Rural & $107(23.3 \%)$ \\
\hline \multirow[t]{4}{*}{ Educational status } & $\begin{array}{l}\text { No formal } \\
\text { education }\end{array}$ & 217 (47.1\%) \\
\hline & Primary & $126(27.4 \%)$ \\
\hline & Secondary & 85 (18.5\%) \\
\hline & Tertiary & $32(7.0 \%)$ \\
\hline \multirow[t]{4}{*}{ Marital status } & Single & $120(26.0 \%)$ \\
\hline & Married & $193(42.0 \%)$ \\
\hline & Divorced & 62 (13.5\%) \\
\hline & Widowed & 85 (18.5\%) \\
\hline \multirow{2}{*}{$\begin{array}{l}\text { Number of child } \\
\text { /parity/ }\end{array}$} & Having child & $311(67.6 \%)$ \\
\hline & Don't have a child & $149(32.4 \%)$ \\
\hline \multirow[t]{7}{*}{ Occupation } & Self employed & 154 (33.5\%) \\
\hline & House wife & $102(22.2 \%)$ \\
\hline & Not employed & 74 (16.1\%) \\
\hline & $\begin{array}{l}\text { Government } \\
\text { employee }\end{array}$ & $40(8.7 \%)$ \\
\hline & Daily laborer & $41(8.9 \%)$ \\
\hline & $\begin{array}{l}\text { Employee in } \\
\text { private organization }\end{array}$ & $36(7.8 \%)$ \\
\hline & Others $^{c}$ & $13(2.8 \%)$ \\
\hline \multirow{4}{*}{$\begin{array}{l}\text { Monthly income } \\
\text { (in USD) }\end{array}$} & $<35$ & $119(25.8 \%)$ \\
\hline & $35-50$ & $110(23.9 \%)$ \\
\hline & $51-100$ & $113(24.6 \%)$ \\
\hline & $>100$ & 118 (25.7\%) \\
\hline
\end{tabular}

Others $^{\mathrm{a}}=$ Adventist and Jewish; Others ${ }^{\mathrm{b}}=$ SNNP and Gambella; Others ${ }^{\mathrm{c}}=$ student and retired which 43 (93.4\%) were screened after diagnosis for HIV. Among those screened, 40(86.9\%) were screened in the past three years and $7(15.2 \%)$ stated that premalignant cervical lesion was detected in their cervix. Among those who were screened, all the $46(100 \%)$ used the screening service up on health service providers' request.

\section{Factors associated with the uptake of cervical cancer screening}

Independent variables which have been considered for a bivariate analysis were socio-demographic variables (age, religion, ethnicity, residence, educational status, marital status, number of child /parity/, occupation, monthly income), client's awareness, ART status, duration (in year) after diagnose of HIV, time since enrolled to HIV care (in year), and CD4 count. Among these variables, number of child /parity/, age, residence, educational status, marital status, monthly income, duration (in year) after diagnose of HIV, time since enrolled to HIV care (year), and CD4 count had a $p$-value of less than 0.2 in the bivariate analysis. Thus, these variables were considered for the multivariable analysis. In the multivariable analysis, HIV positive women who had children, those who attended formal education, women whose HIV status was diagnosed ten years ago, and women whose CD4 cell count was less than or equal to $200 \mathrm{cell} / \mathrm{mm} 3$ had statistically significant association with uptake of Cervical Ca screening (Table 2).

The study participants who had children were three times $(\mathrm{AOR}=3.02,95 \% \mathrm{CI}: 1.22-7.46)$ more likely to be screened for cervical $\mathrm{Ca}$ than those who had no children. The odds of being screened for Cervical Ca among HIV positive women were four times $(\mathrm{AOR}=3.92$, 95\%CI:1.70-8.99) higher in women on primary level education, four times $(\mathrm{AOR}=3.84,95 \% \mathrm{CI}$ : 1.50-9.83) higher in women on secondary level education, and four times $(\mathrm{AOR}=4.16,95 \% \mathrm{CI}: 1.24-13.98)$ higher in women on tertiary level education as compared to those who had no formal education.

HIV positive women whose HIV diagnosis was made ten years or more back were nearly three times $(\mathrm{AOR}=$ 2.71, 95\% CI:1.06-6.97) more likely to be screened for cervical $\mathrm{Ca}$ than those whose HIV diagnosis was made within the past five years ( $<5$ years). Women who had less than or equal to $200 \mathrm{cell} / \mathrm{mm} 3 \mathrm{CD} 4$ count were five times $(\mathrm{AOR}=5.29,95 \% \mathrm{CI}: 2.58-10.83)$ more likely to be screened for cervical $\mathrm{Ca}$ than those who had more than 200cell/mm3 CD4 count (Table 2).

\section{Discussion}

Cervical screening for precancerous lesion is recommended especially for high risk people, like HIV positive individuals so as to take appropriate measures timely. In 
Table 2 Bivariate and multivariable analysis for the uptake of Cervical Ca screening among HIV positive women attending adult ART clinic in Gondar university referral hospital, Northwest Ethiopia, April 2016 ( $n=460)$

\begin{tabular}{|c|c|c|c|c|c|}
\hline \multirow[t]{2}{*}{ Variables } & \multirow[t]{2}{*}{ Category } & \multicolumn{2}{|c|}{ Cervical Ca screening uptake } & \multirow[t]{2}{*}{$\operatorname{COR}(95 \% \mathrm{Cl})$} & \multirow[t]{2}{*}{$\mathrm{AOR}(95 \% \mathrm{Cl})$} \\
\hline & & $\overline{Y e s}$ & No & & \\
\hline \multirow[t]{2}{*}{ Parity } & 0 & 7 & 142 & 1.00 & 1.00 \\
\hline & $>/=1$ & 39 & 272 & $2.90(1.267-6.67)^{\mathrm{a}}$ & $3.02(1.22-7.46)^{\mathrm{a}}$ \\
\hline \multirow[t]{2}{*}{ Residence } & Rural & 5 & 102 & 1.00 & \\
\hline & Urban & 41 & 312 & $2.68(1.03-6.97)$ & \\
\hline \multirow[t]{5}{*}{ Age in year } & $18-24$ & 1 & 28 & $0.08(0.01-1.05)$ & \\
\hline & $25-34$ & 10 & 186 & $0.12(0.04-0.44)^{a}$ & \\
\hline & $35-44$ & 24 & 140 & $0.38(0.12-1.18)$ & \\
\hline & $45-54$ & 6 & 49 & $0.27(0.07-1.04)$ & \\
\hline & $>/=55$ & 5 & 11 & 1.00 & \\
\hline Educational & No formal education & 12 & 205 & 1.00 & 1.00 \\
\hline \multirow{3}{*}{ Level } & Primary & 18 & 108 & $2.85(1.32-6.13)^{a}$ & $3.92(1.70-8.99)^{\mathrm{a}}$ \\
\hline & Secondary & 11 & 74 & $2.54(1.07-6.00)^{\mathrm{a}}$ & $3.84(1.50-9.83)^{\mathrm{a}}$ \\
\hline & Tertiary & 5 & 27 & $3.16(1.03-9.67)^{\mathrm{a}}$ & $4.16(1.24-13.98)^{a}$ \\
\hline \multirow[t]{4}{*}{ Marital status } & Single & 6 & 114 & 1.00 & \\
\hline & Married & 22 & 171 & $2.44(0.96-6.22)$ & \\
\hline & Divorced & 8 & 54 & $2.82(0.93-8.52)$ & \\
\hline & widowed & 10 & 75 & $2.53(0.88-7.26)$ & \\
\hline \multirow{4}{*}{$\begin{array}{l}\text { Monthly income } \\
\text { (in USD) }\end{array}$} & $<35$ & 9 & 110 & 1.00 & \\
\hline & $35-50$ & 7 & 103 & $0.83(0.29-2.31)$ & \\
\hline & $51-100$ & 15 & 98 & $1.871(0.78-4.47)$ & \\
\hline & $>100$ & 15 & 103 & $1.78(0.75-4.24)$ & \\
\hline \multirow{3}{*}{$\begin{array}{l}\text { Diagnosed for HIV } \\
\text { (year) }\end{array}$} & $<5$ & 23 & 250 & 1.00 & 1.00 \\
\hline & $5-9$ & 13 & 134 & $1.06(0.52-2.15)$ & $0.68(0.32-1.47)$ \\
\hline & $>=10$ & 10 & 30 & $3.62(1.58-8.34)^{a}$ & $2.72(1.06-6.97)^{a}$ \\
\hline \multirow{3}{*}{$\begin{array}{l}\text { Since enrolled to HIV care } \\
\text { (year) }\end{array}$} & $1-4$ & 22 & 253 & 1.00 & \\
\hline & $5-9$ & 17 & 140 & $1.39(0.72-2.72)$ & \\
\hline & $>=10$ & 7 & 21 & $3.83(1.47-10.01)^{a}$ & \\
\hline \multirow{2}{*}{$\begin{array}{l}\text { CD4 count } \\
\left(\text { cell/ } / \mathrm{mm}^{3}\right)\end{array}$} & $<=200$ & 19 & 53 & $4.79(2.49-9.22)^{b}$ & $5.29(2.59-10.83)^{b}$ \\
\hline & $>200$ & 27 & 361 & 1.00 & 1.00 \\
\hline
\end{tabular}

${ }^{\mathrm{a}} P$-value: $0.05-0.001 ;{ }^{\mathrm{b}}$ P-value: $<0.001$

this study, the uptake of premalignant cervical cancer screening among HIV positive women was $10 \%$ which is nearly similar to that of the studies conducted in Addis Ababa 12\% [14] and Nigeria 9\% [15]. However, this finding is lower than the study findings in Kenya 84\% [9], South Africa 32\% [10], Italy 91\% [11] and 54\% [16], Canada $82 \%$ [17], and USA $84 \%$ [18], 78\% [19], 85.6\% [20]. This variation could be due to different socio demographic and economic status of the study participants as well as the countries. For example, the educational level of the respondents and their level of awareness about cervical $\mathrm{Ca}$ and its screening program were very low in this study. Though not studied, level of health service providers' commitment in providing information, education, and counseling (IEC) and the screening service might be the reason for low uptake the screening service. Another possible reason for the difference between this study and South Africa's study might be the different data collection technique used. In contrast to ours, self-administered questionnaire was used in South Africa. In Kenya, the availability of free cervical cancer screening program, prevention services and continuous provision of health education about cervical cancer and screening in the area could be the main reasons for the high uptake of Cervical Ca screening. The difference might also be the length of time since the establishment of Cervical Ca screening service and the integration of premalignant cervical cancer screening 
with HIV care in high resource countries. In Ethiopia, cervical cancer screening sites were very few and limited to comprehensive specialized hospitals, and cervical $\mathrm{Ca}$ screening service was initiated just two years back, and continuous and organized health education and awareness creation programs were not well established.

In this study, factors significantly associated with the uptake of cervical cancer screening among HIV positive women were educational status, parity, length of time since HIV was diagnosed, and recent CD4 cell count (Table 2). Educated women can have a better awareness about cervical cancer and its screening, mostly have decision making power, and better health care seeking initiative than non-educated which in turn can result in the utilization of the screening service. In this study, HIV positive women who had formal education (primary, secondary and tertiary) were nearly four times more likely to be screened for Cervical $\mathrm{Ca}$ as compared to women who did not attend formal school. The same association was observed in a study done in Italy [11].

HIV positive women who had children were three times more likely to be screened for cervical cancer than those who had no children. This could be due to the fact that women who had children might visit health care facilities more frequently in addition to their routine HIV care follow up than nulliparous. As a result, they might have chances of getting information and advice to use the screening service from health professionals.

HIV positive women with recent CD4 count of $</=200$ cell $/ \mathrm{mm} 3$ were five times more likely to be screened for cervical Ca than those whose CD4 cell count was $>200$ cell/mm3. Women with lower CD4 count might have advanced WHO clinical stage, they might have been diagnosed as HIV positive a long time ago and might have frequently developed opportunistic infections. Thus, they might make frequent health institution visits and be advised or counseled to be screened for cervical $\mathrm{Ca}$. However, this finding contradicts the finding of a study conducted in Emilia-Romagna, Northern Italy [11].

Women who were diagnosed as HIV positive ten years back or more were nearly three times more likely to be screened for cervical Ca than women who were diagnosed in the past five years. Such women might attend health care for longer duration and might have repeated contact with health care providers for the routine HIV care and treatment services as well as for other medical conditions. Hence, they could have the chance of getting information from health care providers and peers and have better awareness about cervical cancer and its screening, which might in turn make them have better utilization of the screening service. This is in line with a study done in Kenya [9] and Northern Italy [11].
The possible limitation of this study could be the non generalizability of the findings to all HIV positive women attending care and treatment for HIV infection in public health institutions in Gondar city since the data were taken from clients attending only the Gondar University Referral Hospital where a cervical cancer screening program is available. Additionally, the authors did not assess factors from the heath service providers' side, for example, whether they provided information and invited all HIV positive women for screening or not.

\section{Conclusions}

In this study, the uptake of cervical cancer screening was very low. Educational status, parity, number of years after being diagnosed as HIV positive, and CD4 count were predictors of cervical cancer screening. Health care workers and cervical cancer prevention and control program coordinators and implementers need to integrate the screening service to the routine care and treatment and provide counseling services. It is also important to increase women's awareness about the disease and the importance of screening. So as to explore the root causes for the low utilization of precancerous stage of cervical Ca screening service, conducting a study on the supply side with a qualitative component is mandatory.

\section{Additional files}

Additional file 1: English version of the questionnaire. (DOCX $38 \mathrm{~kb}$ )

Additional file 2: Amharic version of the questionnaire. (DOCX $43 \mathrm{~kb}$ )

\section{Abbreviations}

AOR: Adjusted Odds Ratio; ART: Anti-Retroviral Therapy; Ca: Cancer; CD4: Cell Differentiation 4; Cl: Confidence Interval; HAART: Highly Active Antiretroviral Therapy; HIV: Human Immunodeficiency Virus; HPV: Human Papilloma Virus; IEC: Information, Education, and Counseling; NGOs: None Governmental Organizations; SD: Standard Deviation; SPSS: Statistical Package for Social Science; USA: United State of America; VCT: Voluntary Counseling and Testing; VIA: Visual Inspection with Acetic Acid; WHO: (World Health Organization)

\section{Acknowledgements \\ The authors would like to thank University of Gondar, College of Medicine and Health Science for their ethical approval. The acknowledgement is also forwarded for the study participants for their valuable information and for data collectors and supervisors for their commitment. \\ Funding \\ University of Gondar funded this project but it has no role for manuscript preparation and publication.}

Availability of data and materials

All the required data are presented in the main paper.

Authors' contributions

ADN, MAW, and AAG developed the proposal; ADN acquired the data; ADN, MAW, and AAG were involved in the analysis, write up, and manuscript preparation. All authors have read and approved the manuscript. 


\section{Ethics approval and consent to participate}

Ethical approval was obtained from the Institutional Review Board (IRB) of University of Gondar, College of Medicine and Health Sciences, Department of Internal Medicine. Since it is a cross-sectional study, this study does not have risk on participants. Hence, the review board accepted and approved to use verbal consent. Communication with department heads and unit leaders of Gondar University Referral Hospital adult ART Clinic was held through a formal letter. Adequate information about the purpose and importance of the study, the risk and benefit of the study, and their right not to participate or withdraw at any time from the study was given to the study participants first by the data collectors. Finally, data were collected after informed verbal consent was obtained. Confidentiality was maintained throughout the study by excluding their identification in the questionnaire and by doing the interview in private.

\section{Competing interests}

The authors declare that they have no competing interests.

\section{Publisher's Note}

Springer Nature remains neutral with regard to jurisdictional claims in published maps and institutional affiliations.

\section{Author details}

${ }^{1}$ Gondar University Hospital, Gondar City, Ethiopia. ${ }^{2}$ College of Medicine and Health Science, Gynecology and Obstetrics Department, University of Gondar, Gondar City, Ethiopia. ${ }^{3}$ College of Medicine and Health Science, Reproductive Health Department, University of Gondar, Gondar City, Ethiopia.

Received: 2 September 2016 Accepted: 24 May 2018

Published online: 07 June 2018

\section{References}

1. CDC. Basic information about gynecologic cancers. 2014

2. WHO/IARC. GLOBOCAN Cancer Fact Sheets: Cervical cancer, Estimated Incidence, Mortalityand Prevalence Worldwide in 2012. 2015.

3. WHO. Human papillomavirus (HPV) and cervical cancer: fact sheet. Updated June 2016.

4. ICO Information Centre on HPV and Cancer Human Papillomavirus and Related Diseases Report. 2015.

5. Bruni L, Barrionuevo-Rosas L, Albero G, Serrano B, Mena M, Gómez D, Muñoz J, Bosch FX, de Sanjosé S. ICO/IARC Information Centre on HPV and Cancer (HPV Information Centre). Ethiopia: Human Papillomavirus and Related Diseases in Ethiopia. Summary Report 27 July 2017.

6. American cancer society. Cancer Facts \& Figures 2015

7. Cancer IICoHa. Ethiopia. Human Papillomavirus and Related Cancers, Fact Sheet 20152015.

8. World health organization. Comprehensive cervical Cancer Control 2014

9. Rosser Jl, Njoroge B, Huchko MJ. Cervical Cancer screening knowledge and behavior among women attending an urban HIV Clinic in Western Kenya. J Canc Educ. 2015;30:569-72

10. Johanna E. Maree, Kefliwe A. Moitse. Exploration of knowledge of cervical cancer and cervical cancer screening amongst HIV-positive women. 2014.

11. Maso LD, Franceschi S, Lise M, de' Bianchi PS, Polesel J, Ghinelli F, et al. RSeeselafrc-hr aertpicleorted history of pap-smear in HIV-positive women in northern Italy: a cross-sectional study. BMC Cancer. 2010;10(310):2

12. World Health Organization. WHO guidelines for screening and treatment of precancerous lesions for cervical cancer prevention 2013

13. Ethiopian FMOH. NATIONAL CERVICAL CANCER PREVENTION TRAINING PACKAGE. 2015.

14. Belete $\mathrm{N}$, Tsige $\mathrm{Y}$, Mellie $\mathrm{H}$. Willingness and acceptability of cervical cancer screening among women living with HIV/AIDS in Addis Ababa, Ethiopia: a cross sectional study. Gynecologic Oncology Research and Practice. 2015;2:6.

15. Oliver C, Ezechi, Gab-Okafor CV, Ostergren PO, Pettersson KO. Willingness and acceptability of cervical cancer screening among HIV positive Nigerian women. BMC Public Health. 2013;12(46):4.

16. Serraino D, Pavia C, Navarr A, Piselli P, Pisani G, Scuderi M, et al. Knowledge and use of Papanicolaou test among HIV-positive women. Publication of the International Union Against Cancer. 2005;115:1009-10.
17. Andany N, Liu J, Remis R, Kaul R, ML WET. Rates and Correlates of SelfReported Pap Testing in African-Caribbean-Black HIV-Positive Women in Ontario. Canada AIDS \& Clinical Research. 2014;5(11):3.

18. Lisa TW, Shalanda AB, Heather MB, Daniela BF, Sharon MB, Gweneth B, et al. Cervical Cancer prevention knowledge and abnormal pap test experiences among women living with HIV/AIDS. J Canc Educ. 2015;30:213-9.

19. Frazier EL, Madeline Y, Sutton Y, Tie U, McNaghten AD, Blair JM, Skarbinski J. Screening for cervical Cancer and sexually transmitted diseases among HIVinfected women. J Women's Health. 2016;25(2):126.

20. Ogunwale AN, Coleman MA, Sangi-Haghpeykar H, Valverde I, Montealegre J, Jibaja-Weiss $M$, et al. Assessment of factors impacting cervical cancer screening among low-income women living with HIV-AIDS. AIDS Care. 2015;2:491-4.

\section{Ready to submit your research? Choose BMC and benefit from:}

- fast, convenient online submission

- thorough peer review by experienced researchers in your field

- rapid publication on acceptance

- support for research data, including large and complex data types

- gold Open Access which fosters wider collaboration and increased citations

- maximum visibility for your research: over $100 \mathrm{M}$ website views per year

At BMC, research is always in progress.

Learn more biomedcentral.com/submissions 